\title{
Structure-Property Relationship of Fluorinated Co-Poly(Arylene Ether Sulfide)s and Co-Poly(Arylene Ether Sulfone)s for Low-Loss and Low-Birefringence Waveguide Devices
}

\author{
Jae-Wook Kang, Jae-Pil Kim, Jae-Suk Lee, and Jang-Joo Kim
}

\begin{abstract}
Optical properties such as refractive index, birefringence, thermal stability, and optical loss of fluorinated co-poly(arylene ether sulfide)s and co-poly(arylene ether sulfone)s were investigated, and they are related to the molecular structure of the polymers. The refractive index of the optical polymers varies in the range of 1.51 1.60, and its variation is well described by a Lorentz-Lorenz equation. Their birefringence varies between $0.0027 \sim 0.0039$ for the sulfides series and between $0.0009 \sim 0.0025$ for the sulfone series at a $1.55-\mu \mathrm{m}$ wavelength, respectively. The birefringence is analyzed based on the microscopic anisotropic ratio of the polarizability of the molecular repeating unit resulting in good linear relationship between them within the polymer groups. This result implies that the molecular calculation can be utilized to design polymers with low birefringence. The propagation losses of the optical polymers were $0.1 \sim 0.3$ and $0.2 \sim 0.5$ $\mathrm{dB} / \mathrm{cm}$ at the wavelength of 1.3 and $1.55 \mu \mathrm{m}$, respectively. The optical losses are inversely proportional to fluorine content. The polymers have good thermal stability upon long-term thermal stress at $100{ }^{\circ} \mathrm{C}$ for $1000 \mathrm{~h}$ and short-term thermal stress at 300 ${ }^{\circ} \mathrm{C}$ for $1 \mathrm{~h}$.
\end{abstract}

Index Terms-Fluorinated poly(arylene ether sulfide)s, fluorinated poly(arylene ether sulfone)s, low-birefringence, low-loss, optical polymer waveguides, thermally stable.

\section{INTRODUCTION}

$\mathbf{P}$ OLYMER optical waveguides are attractive as optical components in optical interconnects and optical communication systems because of their potential of easy low-temperature and low-cost fabrication. The key requirements of optical waveguide materials include low optical loss in the infrared (IR) region, high

Manuscript received July 16, 2003. This work was supported in part by the MOCIE (Ministry of Commerce Industry and Energy) through the Industrial Basic Researches program and by the MOE (Ministry of Education) through the BK 21 project.

J.-W. Kang was with the Department of Materials Science and Engineering, Kwangju Institute of Science and Technology (K-JIST), Kwangju 500-712, Korea. He is now with the Department of Materials Science and Engineering, University of Washington, Seattle, WA 98195 USA.

J.-P. Kim is with the Korea Photonics Technology Institute (KOPTI), Kwangju 500-210, Korea.

J.-S. Lee is with the Department of Materials Science and Engineering, Kwangju Institute of Science and Technology (K-JIST), Kwangju 500-712, Korea.

J.-J. Kim is with the School of Materials Science and Engineering, Seoul National University, Seoul 151-744, Korea (e-mail: jjkim@snu.ac.kr).

Digital Object Identifier 10.1109/JLT.2004.834980 thermal stability, refractive-index controllability, low birefringence, and good adhesion with silicon substrates. Hydrocarbon polymers have high optical loss in the IR communication region due to the vibrational overtones of the carbon-hydrogen (C-H) bond. Optical loss is significantly reduced by substitution of hydrogen in the $\mathrm{C}-\mathrm{H}$ bond by fluorine or deuterium. Many polymers such as deuterated or fluorinated acrylate [1], [2], benzocyclobutene [3], perfluorocyclobutane [4], cross-linkable fluorinated dendrimer [5], fluorinated polyimide [6]-[9], deuterated polyfluoromethacrylate [10], deuterated polysiloxane [11], polycarbonate [12]-[14], fluorinated poly(arylene ether) [15] and fluorinated poly(arylene ether sulfides) [16], [17] have been synthesized for optical waveguide applications.

Fluorinated poly(arylene ether)s developed for interlayer dielectric materials are good candidates for optical waveguide devices due to their excellent thermal stability, mechanical properties, and low absorption at the near-IR region [18], [19]. However, the material has some drawbacks, such as poor adhesion to substrates. This paper describes the structure-property relationships of fluorinated co-poly(arylene ether sulfide)s and co-poly(arylene ether sulfone)s for low-loss and low-birefringence polymeric optical waveguides. An attempt is made to establish structure-property relationships by relating the chemical structures of individual fluorinated polymers to their optical properties, such as refractive index, birefringence, and optical loss. These polymers have high optical transparency in the IR region because of the replacement of $\mathrm{C}-\mathrm{H}$ bonds with $\mathrm{C}-\mathrm{F}$ bonds. In addition, these polymers have high thermal stability, good processability, and good refractive-index controllability upon changing the copolymer composition. Inclusion of sulfide and sulfone groups in the polymers improves adhesion to silicon substrates. These properties allow us to fabricate low-loss and thermally stable single-mode optical waveguides and a variety of optical devices, such as straight channel waveguides, directional couplers, power splitters, and other optical devices [20].

\section{EXPERIMENTAL}

\section{A. Materials}

Cross-linkable fluorinated co-poly(arylene ether sulfide)s and co-poly(arylene ether sulfone)s were synthesized by the 


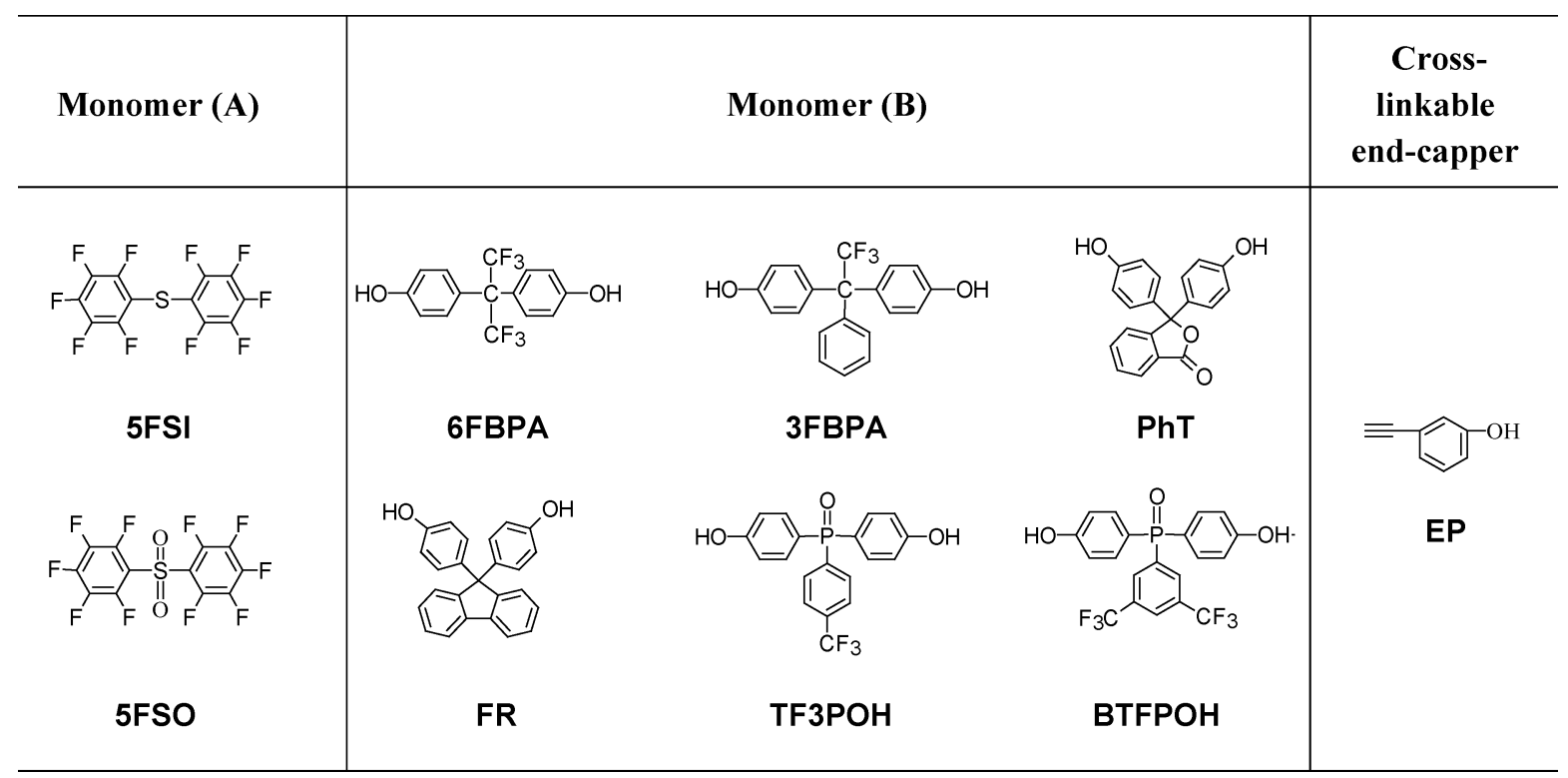

Fig. 1. Chemical structure of co-poly(arylene ether sulfide)s and co-poly(arylene ether sulfone)s. Copolymers were obtained by the combination of monomers (A) and (B) and cross-linkable end capper.

copolymerization of monomers (A) and (B) and the cross-linkable end capper shown in Fig. 1. They include pentafluorophenylsulfide (5FSI), pentafluorophenylsulfone (5FSO) as monomers (A); 4,4'-(hexafluoroisopropylidene)diphenol (6FBPA), 4,4'-(trifluoromethylphenylisopropylidene)diphenol (3FBPA), 9-9'-Bis(4-hydroxyphenyl)fluorene (FR), phenolphthalein $(\mathrm{PhT}), \quad$ 4-trifluoromethylphenyl-4', $4^{\prime \prime}$-(bishydroxyphenyl)phosphine oxide (TF3POH), 3,5-bis(trifluoromethyl)phenyl- $4^{\prime}, 4^{\prime \prime}$-(bishydroxypheyl)phosphine oxide (BTFPOH) as monomers (B); and 3-ethynylphenol (EP) as the cross-linkable end capper. The molecular structure of the building blocks of the cross-linkable fluorinated co-poly(arylene ether sulfide)s and co-poly(arylene ether sulfone)s are shown in Fig. 1. The sulfide and sulfone group in the polymer were introduced to improve adhesion to $\mathrm{Si}$ substrates. To increase the solvent resistance during the multilayer overcoating, we introduced the 3-ethynylphenol (EP) in the polymers as a cross-linkable end capper. The number-average molecular weights $\left(M_{n}\right)$ and polydispersities $\left(M_{w} / M_{n}\right)$ of the polymers were in the range of $12000 \sim 25000$ and $2.2 \sim 3.2$ with polystyrene standards, respectively. Details of the synthetic procedure were reported elsewhere [16], [21].

\section{B. Measurement}

The refractive indexes $n_{\mathrm{TE}}$ and $n_{\mathrm{TM}}$ of the polymer films were measured with a Sairon SPA-3000 prism coupler at the wavelength of $0.633,0.83,1.3$, and $1.55 \mu \mathrm{m}$. This prism coupler has the resolution of $\pm 2 \times 10^{-4}$, which was confirmed using a standard sample (fused silica, $n=1.44402$ at $1.55 \mu \mathrm{m}$ ) with the accuracy of $\pm 0.5 \times 10^{-5}$. To measure the refractive index and fabricate optical waveguides, the polymers were coated on $\mathrm{Si}$ substrates by spin-casting the polymer solution dissolved in cyclohexanone at the concentration of $30 \sim 50 \mathrm{wt} . \%$. The solution was filtered with a $0.2-\mu \mathrm{m}$ Teflon membrane filter before spin-coating. After coating, the polymer films were baked at 270 ${ }^{\circ} \mathrm{C}$ for $2 \mathrm{~h}$ on a hotplate in a nitrogen atmosphere to produce the

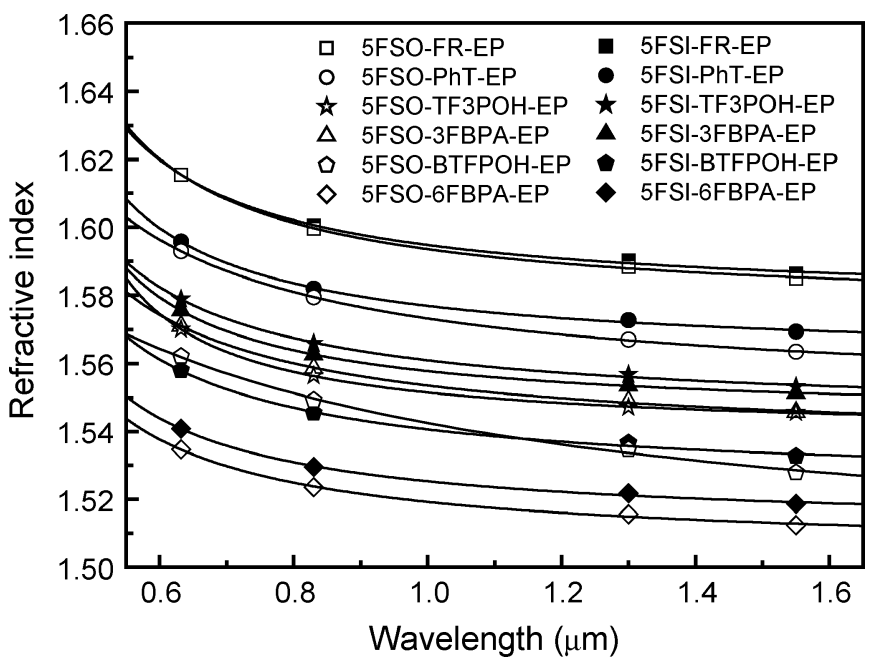

Fig. 2. Refractive index of various fluorinated polymers for TE polarization as a function of wavelength. The experimental data (point) is well described with Sellmeier's equation (solid line).

films with the thickness of $1 \sim 15 \mu \mathrm{m}$. The various combinations of monomers selected from (A) and (B) and cross-linkable end capper allows precise tailoring of the refractive index.

Low optical loss in the IR region is one of the key requirements of optical waveguides materials. The high-index liquid immersion technique was employed to measure the absorption loss of the synthesized materials using a Sairon SPA-3000 [22]. In the technique, light is coupled to a slab waveguide by prism coupling. After propagating a certain distance, the light is outcoupled from the waveguide by immersing it in a high-index liquid, and the out-coupled optical power is measured as a function of the propagation distance.

The loss spectra of the optical waveguides were measured in the range of 1100-1700 nm. Broad-band light (HP 83 437A) was directly launched into the fabricated straight channel waveguides through a single-mode optical fiber, and output light was monitored with an optical spectrum analyzer (HP 86 140B). 
(a)
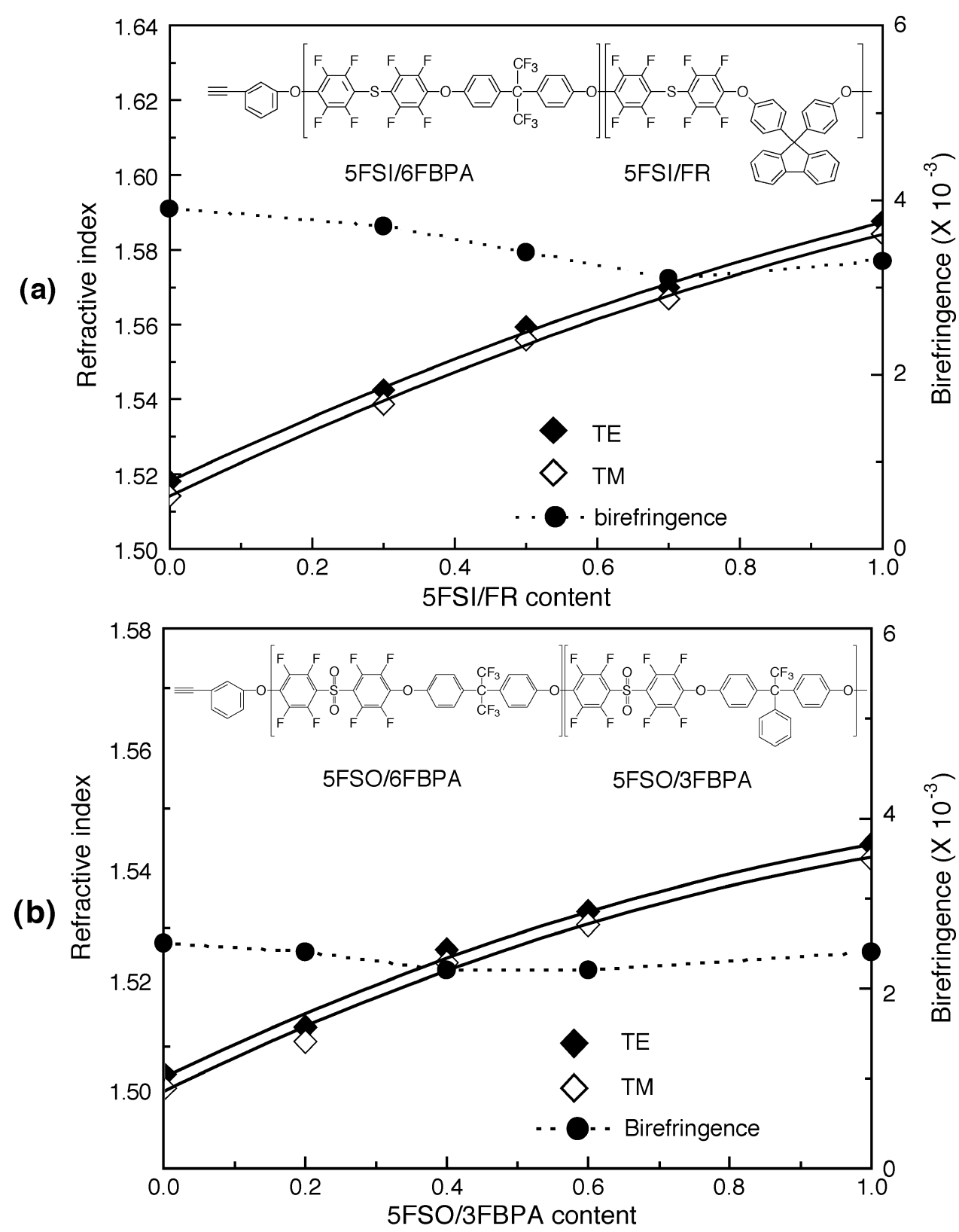

Fig. 3. Dependence of the refractive indexes and birefringence ( $\left.\Delta n=n_{\mathrm{TE}}-n_{\mathrm{TM}}\right)$ of (a) 5FSI/6FBPA-co-5FSI/FR-EP and (b) 5FSO/6FBPA-co-5FSO/3FBPA-EP on co-polymer compositions.

\section{RESULTS AND DISCUSSION}

\section{A. Refractive Index and Birefringence}

The refractive indexes and birefringence $\Delta n=n_{\mathrm{TE}}-n_{\mathrm{TM}}$ were measured with the prism coupler. Fig. 2 shows the refractive index for a number of the basic polymer systems as a function of wavelength. The dispersion of refractive index is well described with Sellmeier's equation given by $n^{2}=\mathrm{A}+\mathrm{B} /\left(1-\mathrm{C} / \lambda^{2}\right)$, where $\mathrm{A}, \mathrm{B}$, and $\mathrm{C}$ are constants. The refractive index can be controlled using the co-polymerization of various monomers, as shown in Fig. 3 for (a) 5FSI/6FBPA-co-5FSI/FR-EP and (b) 5FSO/6FBPA-co-5FSO/3FBPA-EP. The controllability of refractive indexes enables for the use of the materials for core and cladding layers of various optical waveguide devices.
At optical frequencies far from resonance (absorption), the dielectric constant equals the square of the refractive index $\varepsilon(\omega)=$ $n^{2}(\omega)$. Consequently, we can relate the refractive index to the molecular polarizability by the Lorentz-Lorenz equation [23]

$$
\frac{\varepsilon-1}{\varepsilon+2} \cdot \frac{M}{\rho}=\frac{4 \pi}{3} N_{A} \alpha=P \equiv R_{L L}=\frac{\left(n^{2}-1\right)}{\left(n^{2}+2\right)} \cdot \frac{M}{\rho}
$$

where $M$ is the molecular weight of the polymeric repeat unit, $\rho$ is the density, $N_{A}$ is Avogadro's number, $\alpha$ is the molecular polarizability, $P$ is the molar polarization, and $R_{L L}$ is the molar refraction. The equation provides a link between a microscopic quantity (the molecular polarizability) and a macroscopic quantity (the refractive index). From the Lorentz-Lorenz equation, we can sum the atomic and group refraction to give the molar refraction $\left(R_{L L}\right)$ for a repeating unit at the wavelength of $589 \mathrm{~nm}$ 
TABLE I

Calculated Molar Refractions $\left(R_{L L}\right)$ and Refractive Indexes $(n)$ at 589-nm WaVelength, And Calculated Density $\left(\rho_{\text {cal }},\right)$ And Experimentally Measured Density $\left(\rho_{\text {exp. }}\right)$ FOR THE POLYMERS AND GENERAL POLYMERS

\begin{tabular}{|c|c|c|c|c|c|c|c|c|}
\hline Material & $\mathbf{R}_{\mathbf{L L}}$ & $n$ & $\rho_{\text {cal. }}{ }^{\mathbf{b}}$ & Material $^{\mathbf{a}}$ & $\mathbf{R}_{\mathrm{LL}}$ & $n$ & $\rho_{\text {cal. }}^{\mathbf{b}}$ & $\rho_{\text {exp. }}$ \\
\hline 5FSI-6FBPA & 161.52 & 1.5450 & 1.477 & $\mathrm{PAN}^{23}$ & 13.79 & 1.514 & 1.157 & 1.18 \\
\hline 5FSI-3FBPA & 181.32 & 1.5809 & 1.402 & $\mathrm{PMMA}^{23}$ & 24.75 & 1.490 & 1.169 & 1.17 \\
\hline 5FSI-PhT & 182.55 & 1.6012 & 1.383 & $\mathrm{PS}^{23}$ & 33.77 & 1.591 & 1.031 & 1.05 \\
\hline 5FSI-FR & 200.41 & 1.6214 & 1.350 & Nylon $66^{23}$ & 63.23 & 1.475 & 1.007 & 1.07 \\
\hline 5FSO-6FBPA & 165.06 & 1.5387 & 1.493 & $\mathrm{PC}^{23}$ & 72.89 & 1.585 & 1.168 & 1.20 \\
\hline 5FSO-3FBPA & 184.86 & 1.5755 & 1.422 & $\mathrm{PFCB}^{24}$ & 121.81 & 1.488 & 1.535 & 1.522 \\
\hline 5FSO-PhT & 186.09 & 1.5976 & 1.409 & Cytop $\mathbb{R}^{23}$ & 26.23 & 1.34 & 2.09 & 2.03 \\
\hline 5FSO-FR & 203.95 & 1.6218 & 1.382 & $6 \mathrm{FDA}^{-\mathrm{TFDB}^{7}}$ & 151.03 & $1.53-1.54$ & $\begin{array}{c}1.489- \\
1.512\end{array}$ & 1.47 \\
\hline
\end{tabular}

a polyacrylonitrile (PAN), poly(propylene sulfide) (PPS), poly(methymethacrylate) (PMMA), polystyrene (PS), poly(hexamethylene adipamide) (Nylon 66), poly(2,2-propane bis(4-phenyl) carbonate) (PC), 1,1,1-triphenyl perfluorocyclobutyl ether (PFCB), poly(perfluoroethylene-co-butenyl vinyl ether) (Cytop $\left.{ }^{\circledR}\right), 2,2$ '-bis(3,4-dicarboxyphenyl)hexafluoropropane dianhydride (6FDA), 2,2bis(trifluoromethyl)-4,4'-diaminobiphenyl (TFDB).

${ }^{\mathrm{b}}$ Calculated density of polymer from the slope of Figure 4.

${ }^{c}$ Experimentally measured density of polymer.

[23]. The refractive indexes at 589-nm wavelength were calculated from the Sellmeier's equation shown in Fig. 2. The molar refraction and refractive indexes at 589-nm wavelength are summarized in Table I, and they are plotted in Fig. 4. The molar refraction is linearly proportional to $M\left(n^{2}-1\right) /\left(n^{2}+2\right)$, indicating that the Lorentz-Lorenz equation relates the refractive index to molar refraction very well. The density of the polymers can be calculated from the slope in Fig. 4, and they are in the range of 1.35-1.50, as summarized in Table I. The densities are reasonable if we consider that the polymers are fluorinated and contain a sulfone or sulfide group. In the table, the calculated density of common polymers such as polymethylmethacrylate, polystyrene, polyamides, polycarbonate, perfluorocyclobutane (PFCB), Cytop, and polyimide (6FDA-TFDB) are included and compared with the experimentally obtained density [7], [23], [24]. The calculate densities match very well with the experimental data. This good relationship between the molar refraction (the polarizability) and $M\left(n^{2}-1\right) /\left(n^{2}+2\right)$ suggests that refractive index can be predicted prior to synthesis from the molecular structure if density is known [25]. The accuracy of the refractive index can be $\sim 0.005$ for a 0.01 density difference, which is an acceptable resolution prior to synthesis for waveguide applications.

The birefringences of various co-polymers are summarized in Table II. By changing the co-polymer composition, the birefringence was reduced significantly down to 0.0009 at a wavelength

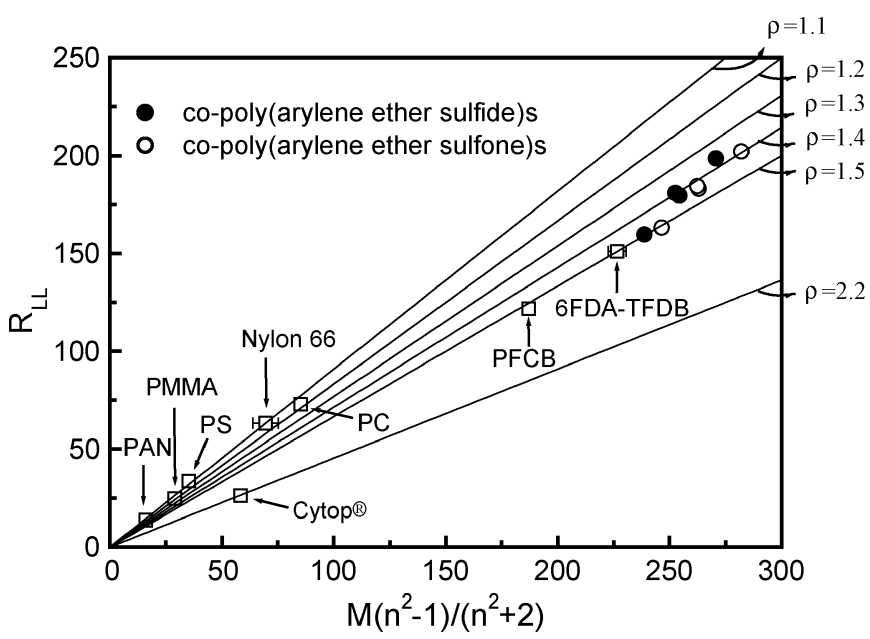

Fig. 4. Calculated molar refraction $\left(R_{L L}\right)$ dependence on $M\left(n^{2}-1\right) /\left(n^{2}+\right.$ 2) with Lorentz-Lorenz equation for general polymers, co-poly(arylene ether sulfide)s, and co-poly(arylene ether sulfone)s. From the slope $(1 / \rho)$, the density of polymers can be calculated.

of $1.55 \mu \mathrm{m}$. This is much lower than those of fluorinated polyimides [7]. For anisotropic media, which have the difference between the refractive indexes in the two principal directions, the birefringence $(\Delta n)$ must be related to the polarizability difference between the polymer chain axes $\left(\alpha_{x x}, \alpha_{y y}\right)$ and perpendicular to the chain axes $\left(\alpha_{z z}\right)$ and molecular orientations in bulk 
TABLE II

Birefringence $(\Delta n)$ AND THERMAl StABILITY OF Co-Poly (ARYlen Ether Sulfide)S AND CO-POLY (ARYLEN ETHER SULFONE)S

\begin{tabular}{|c|c|c|c|c|c|}
\hline Material & $\begin{array}{r}\Delta \mathrm{n}, \\
\times 10^{-3}\end{array}$ & $\begin{array}{c}\text { Thermal } \\
\text { stability, }{ }^{\circ} \mathrm{C}\end{array}$ & Material & $\begin{array}{r}\Delta \mathrm{n}, \\
\times 10^{-3}\end{array}$ & $\begin{array}{l}\text { Thermal } \\
\text { stability, }{ }^{\circ} \mathrm{C}\end{array}$ \\
\hline 5FSI-6FBPA-EP & 3.9 & $\begin{array}{l}170\left(\mathrm{~T}_{\mathrm{g}}\right) \\
489\left(\mathrm{~T}_{\mathrm{d}}\right)\end{array}$ & 5FSO-6FBPA-EP & 2.5 & $\begin{array}{l}199\left(\mathrm{~T}_{\mathrm{g}}\right) \\
461\left(\mathrm{~T}_{\mathrm{d}}\right)\end{array}$ \\
\hline 5FSI-3FBPA-EP & 3.4 & $\begin{array}{l}175\left(\mathrm{~T}_{\mathrm{g}}\right) \\
485\left(\mathrm{~T}_{\mathrm{d}}\right)\end{array}$ & 5FSO-3FBPA-EP & 2.4 & $\begin{array}{l}237\left(\mathrm{~T}_{\mathrm{g}}\right) \\
424\left(\mathrm{~T}_{\mathrm{d}}\right)\end{array}$ \\
\hline 5FSI-TF3POH-EP & 3.4 & $\begin{array}{l}201\left(\mathrm{~T}_{\mathrm{g}}\right) \\
370\left(\mathrm{~T}_{\mathrm{d}}\right)\end{array}$ & 5FSO-TF3POH-EP & - & - \\
\hline 5FSI-BTFPOH-EP & 2.7 & $\begin{array}{l}205\left(\mathrm{~T}_{\mathrm{g}}\right) \\
395\left(\mathrm{~T}_{\mathrm{d}}\right)\end{array}$ & 5FSO-BTFPOH-EP & 2.4 & - \\
\hline 5FSI-PhT-EP & 3.0 & $\begin{array}{l}230\left(\mathrm{~T}_{\mathrm{g}}\right) \\
479\left(\mathrm{~T}_{\mathrm{d}}\right)\end{array}$ & 5FSO-PhT-EP & 1.2 & $\begin{array}{l}270\left(\mathrm{~T}_{\mathrm{g}}\right) \\
375\left(\mathrm{~T}_{\mathrm{d}}\right)\end{array}$ \\
\hline 5FSI-FR-EP & 2.7 & $\begin{array}{l}223\left(\mathrm{~T}_{\mathrm{g}}\right) \\
487\left(\mathrm{~T}_{\mathrm{d}}\right)\end{array}$ & 5FSO-FR-EP & 0.9 & $\begin{array}{l}272\left(\mathrm{~T}_{\mathrm{g}}\right) \\
435\left(\mathrm{~T}_{\mathrm{d}}\right)\end{array}$ \\
\hline
\end{tabular}

material. In the microscopic view, the quantities of interest are the polarizability components and their anisotropic ratio $(\delta)$ defined by [26]

$$
\delta=\left[\frac{\left(\alpha_{x x}-\alpha_{y y}\right)^{2}+\left(\alpha_{y y}-\alpha_{z z}\right)^{2}+\left(\alpha_{z z}-\alpha_{x x}\right)^{2}}{\left(\alpha_{x x}+\alpha_{y y}+\alpha_{y y}\right)^{2}}\right]^{\frac{1}{2}} .
$$

Thus, the birefringence must be proportional to anisotropic ratio $\delta$ of linear polarizability (microscopic view) and molecular orientations $\Omega$ in bulk material (macroscopic view) as in

$$
\Delta n \propto \delta \cdot \Omega .
$$

If the anisotropic ratio $\delta$ is zero, $\Delta n$ will be zero. Under this condition, molecular orientations in bulk material do not have influence on birefringence. On the other hand, however, if the chain conformations of the polymers are random with no preferred orientation, i.e., $\Omega=0$, the birefringence will be zero because the molecular anisotropic ratio of $\delta$ will be cancelled out in macroscopic scale, resulting in $\Delta n=0$. Recently, the factors influencing birefringence have been widely investigated, such as the spin-coating condition [27], substrate material [27], thermal treatment condition [27], [28], film thickness [27], [29], [31], humidity condition [29], [30], [32], and solvent system [31]. Most of the previously mentioned factors are related to molecular orientations in bulk materials.

In this study, the effect of the molecular structure on the birefringence for various co-polymers is theoretically investigated by relating the molecular structure to the molecular polarizability calculated by the MOPAC (Molecular Orbital Package) program [33] (CAChe Worksystem ver. 5.02, Fujitsu). For the purpose, we assumed that the orientational factor of polymer chain $\Omega$ is equal for all polymer films. It is a reasonable assumption for our system because we used the same solvent, spin-coating condition, thermal treatment, film thickness, and Si substrate. Therefore, we can investigate the relationship between the birefringence $\Delta n$ and anisotropic ratio $\delta$. For the calculation of $\delta$, only one repeating unit was considered [33], and the molecular repeating unit was rotated to have the principal

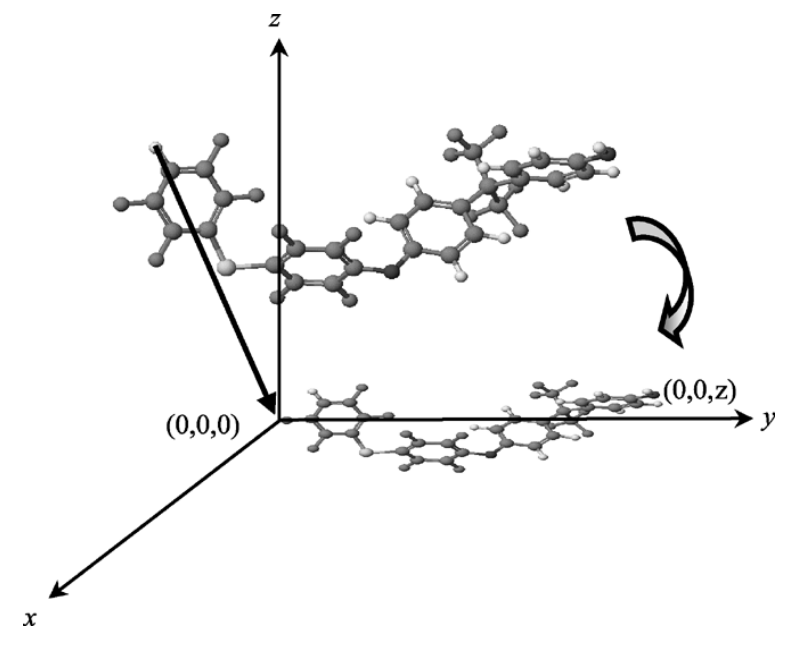

Fig. 5. Movement and rotation of orignal coordinate to the principal axes $x$, $y, z$.

axes $x, y$, and $z$ as shown in Fig. 5. After the rotation, the geometry was optimized using PM5 parameters to calculate the polarizability component $\alpha_{x x}, \alpha_{y y}$, and $\alpha_{z z}$.

Table III summarizes the calculated polarizability components and anisotropic ratio, and Fig. 6 shows a plot between the experimentally obtained birefringences against the calculated anisotropic ratio. The birefringence is more or less proportional to the anisotropic ratio for the co-polymer system. Interestingly enough, however, sulfone containing co-polymer showed a larger proportional constant than sulfide containing co-polymer. It is reasonable because the sulfone group has a larger kink angle. The calculation using more repeating units than one resulted in slight modification in the results at the expense of much longer computational time.

\section{B. Optical Losses of Slab and Channel Waveguides}

The optical losses of fluorinated co-poly(arylene ether sulfide)s and co-poly(arylene ether sulfone)s for slab and channel waveguides were measured at the wavelengths of 1.3 and 
TABLE III

CAlculated Polarizability COMPONENTS $\left(\alpha_{x x}, \alpha_{y y}\right.$, AND $\left.\alpha_{z z}\right)$ AND ANISOTROPIC RATIO $(\delta)$ OF THE REPEATING UNIT OF CO-POLY(ARYLEN ETHER SUlFIDE)S AND CO-POLY(ARYLEN ETHER SUlFONE)S

\begin{tabular}{ccccc}
\hline Material & $\alpha_{x x}$ & $\alpha_{y y}$ & $\alpha_{z z}$ & $\delta$ \\
\hline 5FSI-6FBPA & 61.1 & 31.7 & 30.5 & 0.344 \\
5FSI-BTFPOH & 73.0 & 41.5 & 36.2 & 0.322 \\
5FSI-3FBPA & 62.3 & 37.3 & 41.8 & 0.230 \\
5FSI-TF3POH & 57.4 & 47.2 & 42.7 & 0.125 \\
5FSI-PhT & 58.4 & 35.5 & 47.7 & 0.197 \\
5FSI-FR & 63.1 & 47.5 & 48.8 & 0.132 \\
5FSO-6FBPA & 53.0 & 35.1 & 33.8 & 0.215 \\
5FSO-BTFPOH & 69.6 & 43.7 & 38.0 & 0.271 \\
5FSO-3FBPA & 62.1 & 31.2 & 51.0 & 0.265 \\
5FSO-TF3POH & 69.1 & 35.8 & 48.1 & 0.269 \\
5FSO-PhT & 55.2 & 49.9 & 37.9 & 0.151 \\
5FSO-FR & 58.4 & 47.0 & 54.5 & 0.088 \\
\hline
\end{tabular}

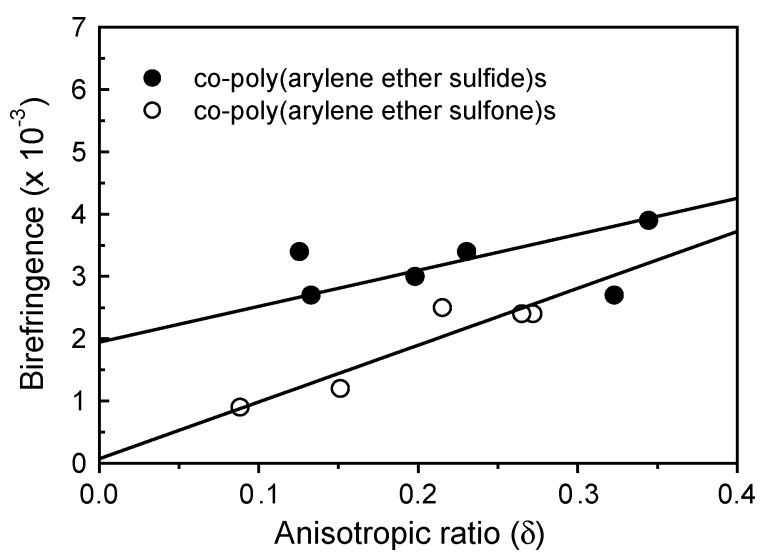

Fig. 6. Dependence of birefringence on anistropic ratio of calculated polarizability for co-poly(arylene ether sulfide)s and co-poly(arylene ether sulfone)s at the wavelength of $1.55 \mu \mathrm{m}$.

$1.55 \mu \mathrm{m}$. The slab waveguides were prepared by spin-coating the materials on a silicon substrate coated with ZP $2145 \mathrm{M}$ ( $n=1.4845$ at a $1.55-\mu \mathrm{m}$ ) layer. After coating, the polymer films were baked at $270{ }^{\circ} \mathrm{C}$ for $2 \mathrm{~h}$ on a hotplate in nitrogen atmosphere to produce the films with the thickness of $6 \sim 8 \mu \mathrm{m}$. Optical absorption loss of the slab waveguides can be obtained from the slope in the Fig. 7. The measured optical loss is close to the absorption loss of the material constituting the waveguide because it does not include the optical loss due to the fabrication imperfections of channel waveguides. The measured losses at 1.3 and $1.55 \mu \mathrm{m}$ for TE and TM polarizations are summarized in Table IV for various polymers. The propagation losses of fluorinated polymers were $0.1 \sim 0.3$ and $0.2 \sim 0.5 \mathrm{~dB} / \mathrm{cm}$ at the wavelengths of 1.3 and $1.55 \mu \mathrm{m}$, respectively. The optical losses of slab waveguides were found to be dependent on fluorine content per repeat unit as shown in Fig. 8. The optical loss decreases with increasing fluorine content. The figure indicates

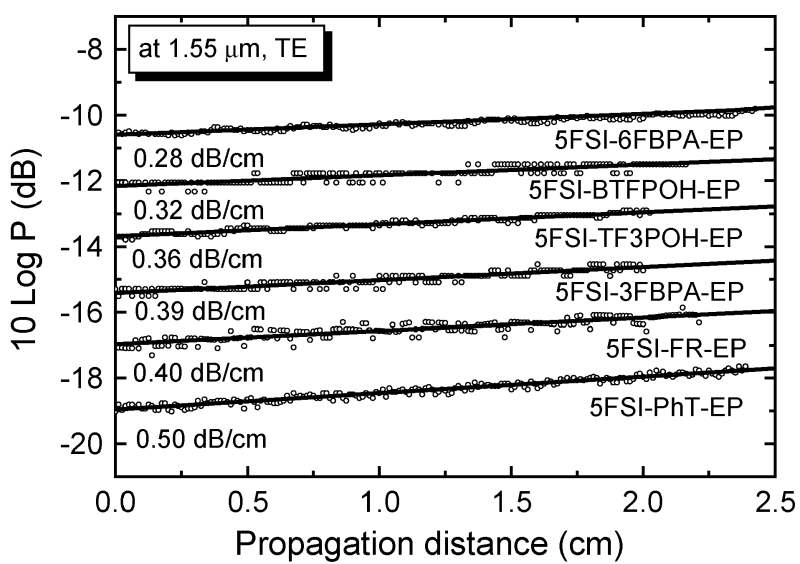

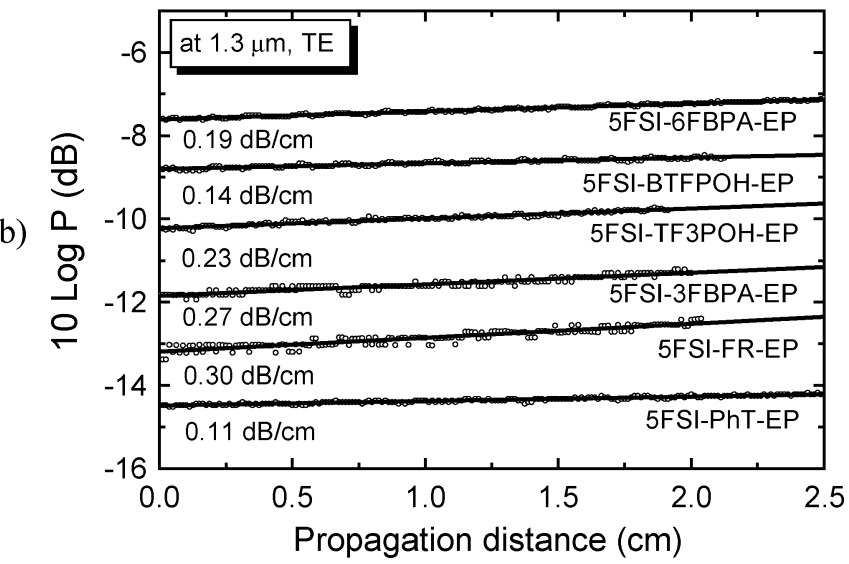

Fig. 7. Optical losses from slab waveguides of co-poly(arylene ether sulfide)s at (a) $1.55 \mu \mathrm{m}$ and (b) $1.3 \mu \mathrm{m}$ for TE polarization measured by the high-index liquid immersion technique.

that the optical loss less than $0.1 \mathrm{~dB} / \mathrm{cm}$ can be obtained with fluorine content of 50 and $60 \mathrm{wt} . \%$ at the wavelengths of 1.3 and $1.55 \mu \mathrm{m}$, respectively.

We also measured the optical loss of single-mode channel waveguides using the cutback method for various materials. The photolithography and RIE processes were used to fabricate the single-mode polymer optical waveguides. A core layer was spin-coated onto a cladding layer on an $\mathrm{Si}$ substrate and baked at $270{ }^{\circ} \mathrm{C}$ for $2 \mathrm{~h}$ in a nitrogen atmosphere. On the core layer, a 100-nm-thick silicon nitride mask was deposited by plasma-enhanced chemical-vapor deposition (PECVD) using $\mathrm{SiH}_{4}$ and $\mathrm{N}_{2}$ at $150{ }^{\circ} \mathrm{C}$. AZ5214 photoresist was spin-coated onto the silicon nitride layer to define the waveguides and patterned using the conventional photolithography. The silicon nitride mask was patterned by RIE using $\mathrm{CF}_{4}$ gas with the developed photoresist as an etch mask, and the pattern was transferred to the core layer to form a ridge/channel waveguide by $\mathrm{O}_{2}$ RIE. Finally, the upper-cladding layer was spin-coated [17]. A scanning electron microscope (SEM) micrograph of a typical fabricated single-mode waveguide is displayed in Fig. 9(b). The results of the optical loss measurement from the channel waveguides made of co-poly(arylene ether sulfide)s and co-poly(arylene ether sulfone)s are shown in Fig. 9(a) and summarized in Table IV for some of the materials. The optical loss due to fabrication imperfections of the channel waveguides can be determined from the difference in the propagation loss between the slab and channel waveguide, and it turns out to be 
TABLE IV

OpticAl Losses of Co-Poly (ARYLENE ETHER Sulfide)S AND Co-Poly(ARYlene Ether Sulfone)S

\begin{tabular}{|c|c|c|c|}
\hline Material & $\mathbf{F} \%{ }^{\mathrm{a}}$ & $\begin{array}{c}\text { Slab waveguide loss, } \\
\mathrm{dB} / \mathrm{cm}\end{array}$ & $\begin{array}{c}\text { Channel waveguide loss, } \\
\mathrm{dB} / \mathrm{cm}\end{array}$ \\
\hline 5FSI-6FBPA-EP & 41.37 & $\begin{array}{l}0.28 \text { (TE), } 0.27 \text { (TM) @ } 1.55 \\
0.19 \text { (TE), } 0.15 \text { (TM) @ } 1.3\end{array}$ & $\begin{array}{c}0.42 \text { (TE), } 0.40(\mathrm{TM}) \\
\text { @ } 1.55\end{array}$ \\
\hline 5FSI-BTFPOH-EP & 39.88 & $\begin{array}{l}0.32 \text { (TE), } 0.30 \text { (TM) @ } 1.55 \\
0.14 \text { (TE), } 0.11 \text { (TM) } @ 1.3\end{array}$ & - \\
\hline 5FSI-TF3POH-EP & 37.19 & $\begin{array}{l}0.36 \text { (TE), } 0.35 \text { (TM) @ } 1.55 \\
0.23 \text { (TE), } 0.20 \text { (TM) @ } 1.3\end{array}$ & $\begin{array}{l}0.53 @ 1.55 \\
0.23 @ 1.3\end{array}$ \\
\hline 5FSI-3FBPA-EP & 35.13 & $\begin{array}{l}0.39 \text { (TE), } 0.38 \text { (TM) @ } 1.55 \\
0.27 \text { (TE), } 0.25 \text { (TM) } @ 1.3\end{array}$ & - \\
\hline 5FSI-FR-EP & 27.48 & $\begin{array}{l}0.40 \text { (TE), } 0.37 \text { (TM) @ } 1.55 \\
0.30 \text { (TE), } 0.27 \text { (TM)@ } 1.3\end{array}$ & $\begin{array}{l}0.55 @ 1.55 \\
0.36 @ 1.3\end{array}$ \\
\hline 5FSI-PhT-EP & 27.48 & $\begin{array}{l}0.50 \text { (TE), } 0.46 \text { (TM) @ } 1.55 \\
0.11 \text { (TE), } 0.08 \text { (TM) } @ 1.3\end{array}$ & $\begin{array}{l}0.78 @ 1.55 \\
0.66 @ 1.3\end{array}$ \\
\hline 5FSO-6FBPA-EP & 39.4 & 0.57 (TE), 0.55 (TM)@ 1.55 & - \\
\hline 5FSO-3FBPA-EP & 33.48 & $\begin{array}{l}0.46 \text { (TE), } 0.45 \text { (TM) @ } 1.55 \\
0.36 \text { (TE), } 0.35 \text { (TM) @ } 1.3\end{array}$ & $\begin{array}{l}0.47 @ 1.55 \\
0.37 @ 1.3\end{array}$ \\
\hline
\end{tabular}

${ }^{a}$ Fluorine content per repeating unit (wt.\%)

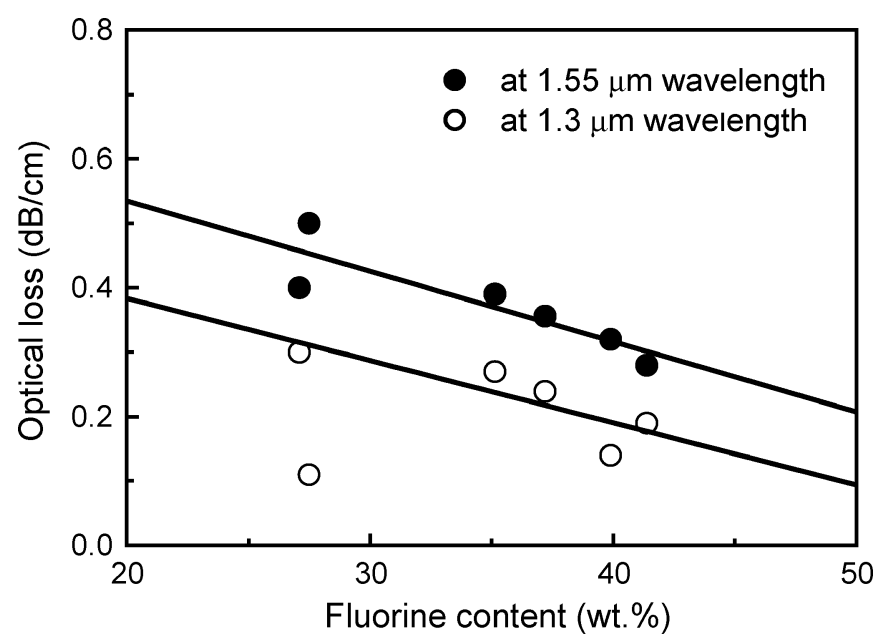

Fig. 8. Dependence of optical losses on fluorine content for slab waveguides of co-poly(arylene ether sulfide)s at 1.3- and $1.55-\mu \mathrm{m}$ wavelengths.

less than $0.2 \mathrm{~dB} / \mathrm{cm}$. Optical losses as low as $0.4 \mathrm{~dB} / \mathrm{cm}$ were obtained for channel waveguides.

\section{Polarization-Dependent Loss}

Because polarization-dependent loss (PDL) of the rib waveguide is one of the main reasons for the polarization dependence of the waveguide devices, the reduction of PDL has been a hot issue in device fabrications. The PDL value is defined as the difference of the optical losses between the TE and TM modes of a channel waveguide. It is thought to be due to different confinement for TE and TM polarizations in channel waveguides. Min et al. [34] reported that PDL increased considerably when the slab-waveguide thickness exceeded a certain size and explained that it is due to a mode coupling between the TM mode of the rib (a)

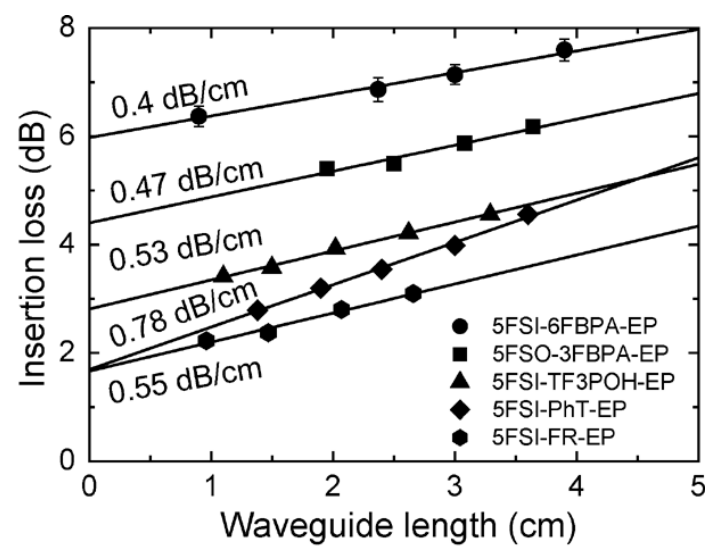

(b)

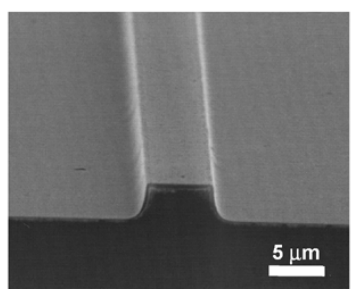

Fig. 9. (a) Propagation loss of single-mode channel waveguides measured by the cutback method and (b) SEM photograph of the fabricated straight waveguide.

waveguide and TE mode of the slab waveguides via anisotropic thermal stress distribution. However, the PDL is a very small value in the channel waveguide due to no phase matching for mode coupling.

An additional contribution of the PDL in channel waveguides comes from the sidewall roughness, which largely depends on the process conditions. The roughness of the etched sidewalls of the waveguide structures should be as small as possible in order to reduce the loss due to light scattering. In this case, the 


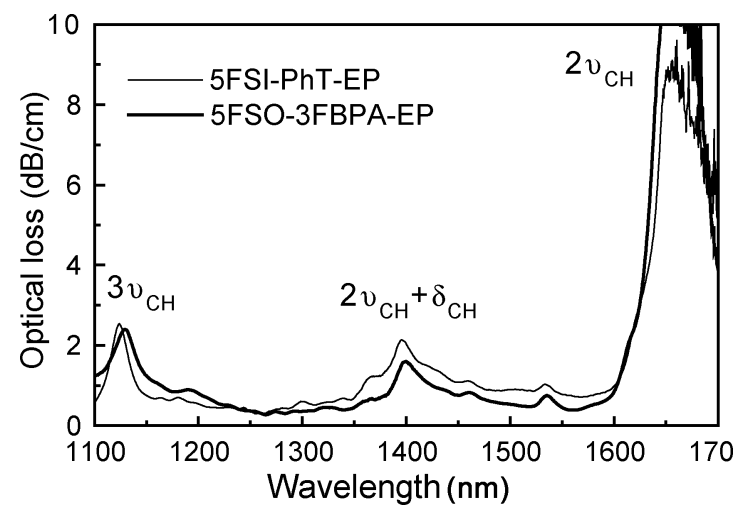

Fig. 10. Loss spectra of optical channel waveguides of 5FSI-PhT-EP and 5FSO-3FBPA-EP.

scattering loss is larger for TE polarization than TM, resulting in the large PDL.

In order to reduce PDL in polymer optical waveguides, the low-birefringence and low-thermal stress of optical polymers, small-sidewall roughness of the channel waveguide, and the well-optimized waveguide structure are required. The PDL value of our fabricated single-mode channel waveguide was $0.02 \mathrm{~dB} / \mathrm{cm}$ at a wavelength of $1.55 \mu \mathrm{m}$. This result indicates that the fabricated waveguide has good optical properties and well-optimized structure.

\section{Loss Spectra in the Infrared Region}

The loss spectra of the optical waveguides of the materials are shown in Fig. 10. Three peaks are observed in the IR regions of the loss spectra of the synthetic polymers: the third harmonics of the stretching vibration of the $\mathrm{C}-\mathrm{H}$ bond $\left(3 \nu_{\mathrm{CH}}, 1.1 \mu \mathrm{m}\right)$; the combination of the second harmonics of the stretching and bending vibration of the $\mathrm{C}-\mathrm{H}$ bond $\left(2 \nu_{\mathrm{CH}}+\delta_{\mathrm{CH}}, 1.4 \mu \mathrm{m}\right)$; and the second harmonics of the stretching vibration of the $\mathrm{C}-\mathrm{H}$ bond $\left(2 \nu_{\mathrm{CH}}, 1.65 \mu \mathrm{m}\right)$. IR regions of transparence exist near 1.3 and $1.55 \mu \mathrm{m}$, the wavelengths of interest for telecommunications.

\section{E. Thermal Stability}

Thermal stability is an important issue for optical components. The thermal stability of the waveguide materials was studied by a variety of techniques such as differential scanning calorimetry (DSC), thermal gravimetric analysis (TGA), refractive-index change at $100{ }^{\circ} \mathrm{C}$, and optical loss measurements at different temperatures $\left(250-380{ }^{\circ} \mathrm{C}\right)$. DSC analysis was performed to study the effect of curing on the $T_{g}$ and the curing properties of the polymers. As the scan number of DSC was increased, the $T_{g}$ increased from $120^{\circ} \mathrm{C}$ to $170{ }^{\circ} \mathrm{C}$ for 5FSI-6FBPA-EP. An intense exothermic peak in the first scan of DSC was observed due to the reaction of ethynyl moiety. In the third scan (as the degree of curing was increased), this exothermic peak disappeared indicating the curing reaction is almost complete during the first two scans in the DSC [16]. The glass transition temperatures of the synthetic polymers were higher than $200{ }^{\circ} \mathrm{C}$ except 5FSI-6FBPA-EP and 5FSI-3FBPA-EP. The thermal decomposition temperature, defined as $5 \%$ weight loss temperature at a heating rate of

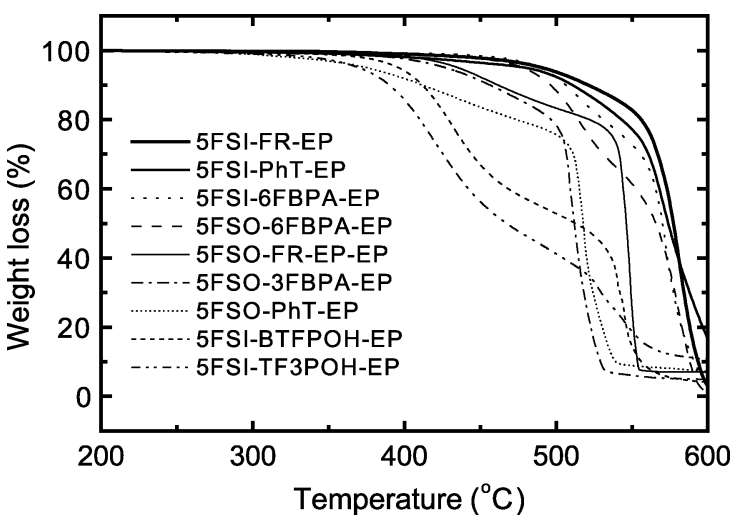

Fig. 11. TGA of the various polymers at a heating rate of $10^{\circ} \mathrm{C} / \mathrm{min}$ in a nitrogen atmosphere.

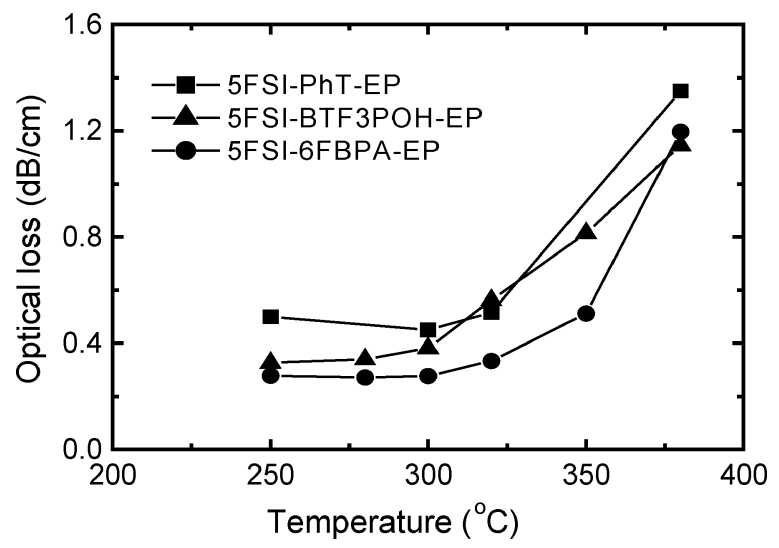

Fig. 12. Optical loss after storing at different temperatures in an air atmosphere for $1 \mathrm{~h}$. Theses polymers are thermally stable up to $300^{\circ} \mathrm{C}$ for $1 \mathrm{~h}$.

$10{ }^{\circ} \mathrm{C} / \mathrm{min}$ in a nitrogen atmosphere, was higher than $400{ }^{\circ} \mathrm{C}$, except 5FSI-TF3POH-EP and 5FSO-PhT-EP, as shown in Fig. 11, which is high enough for optical applications. The refractive index of one of the polymers did not change even after storing at $100{ }^{\circ} \mathrm{C}$ for $1000 \mathrm{~h}$ [17]. These results demonstrate the long-term thermal stability of the polymers.

Short-term thermal stability of the polymers was examined by the measurement of the change of the optical loss after storing the sample at high temperatures for $1 \mathrm{~h}$. The change of optical loss was measured using the high-index liquid immersion technique. The optical loss does not change over a wide range of temperatures up to $300{ }^{\circ} \mathrm{C}$ as shown in Fig. 12, suggesting that our polymers are thermally stable up to $300^{\circ} \mathrm{C}$ for $1 \mathrm{~h}$. Because of yellowing effects, however, the optical losses steeply increase above $320^{\circ} \mathrm{C}$. In conclusion, the polymers have good thermal stability upon long-term thermal stress at $100{ }^{\circ} \mathrm{C}$ for $1000 \mathrm{~h}$ and short-term thermal stress at $300{ }^{\circ} \mathrm{C}$ for $1 \mathrm{~h}$.

\section{CONCULSION}

Optical properties such as refractive index, birefringence, thermal stability, and optical loss of fluorinated co-poly(arylene ether sulfide)s and co-poly(arylene ether sulfone)s were investigated, and they are related to the molecular structure of the polymers. The refractive index of the optical polymers varies in the range of 1.51 and 1.60 , and its variation is well described by the Lorentz-Lorenz equation. Birefringence of 
the polymer-containing sulfone group is lower than the sulfide group containing molecules. Their birefringence varies between 0.0027 and 0.0039 for the sulfide series and between 0.0009 and 0.0025 for the sulfone series at $1.55 \mu \mathrm{m}$ wavelength, respectively. The difference is supposed to come from the difference of the bond angle of the groups leading to more random molecular configuration with the sulfone group. The birefringence is analyzed based on the microscopic anisotropic ratio of the polarizability of the molecular repeating unit, resulting in a good linear relationship between them within the polymer groups (sulfone or sulfide series). This result implies that the molecular calculation can be utilized to design polymers with low birefringence. The propagation losses of optical polymers were $0.1 \sim 0.3$ and $0.2 \sim 0.5 \mathrm{~dB} / \mathrm{cm}$ at the wavelengths of 1.3 and $1.55 \mu \mathrm{m}$, respectively. The optical losses are inversely proportional to fluorine content. The polymers have good thermal stability upon long-term thermal stress at $100{ }^{\circ} \mathrm{C}$ for $1000 \mathrm{~h}$ and short-term thermal stress at $300^{\circ} \mathrm{C}$ for $1 \mathrm{~h}$.

Single-mode channel waveguides were designed by the effective-index method and beam-propagation method (BPM) and fabricated using photolithography and the RIE process. Optical losses of single-mode channel waveguides are slightly higher than slab waveguides because of the fabrication imperfections of the channel waveguides. The difference in the optical loss between the slab and channel waveguides was less than $0.2 \mathrm{~dB} / \mathrm{cm}$.

\section{ACKNOWLEDGMENT}

The authors would like to thank Dr. W. H. Hwang at Zenphotonics for the helpful discussion.

\section{REFERENCES}

[1] B. L. Booth, "Low loss channel waveguides in polymers," J. Lightw. Technol., vol. 7, no. 10, pp. 1445-1453, Oct. 1989.

[2] L. Eldada and L. W. Shacklette, "Advances in polymer integrated optics," IEEE J. Sel. Topics Quantum Electron., vol. 6, no. 1, pp. 54-68, Jan.-Feb. 2000.

[3] C. F. Kane and R. R. Krchnavek, "Benzocyclobutene optical waveguides," IEEE Photon. Technol. Lett., vol. 7, no. 5, pp. 535-537, May 1995.

[4] G. Fischbeck, R. Moosburger, C. Kostrzewa, A. Achen, and K. Petermann, "Single mode optical waveguides using a high temperature stable polymer with low losses in the 1.55 range," Electron. Lett., vol. 33, pp. 518-519, 1997.

[5] H. Ma, A. K.-Y. Jen, and L. R. Dalton, "Polymer-based optical waveguides: Materials, processing, and devices," Adv. Mater., vol. 14, no. 19, pp. 1339-1365, 2002.

[6] K. D. Singer, T. C. Kowalczyk, H. D. Nguyen, A. J. Beuhler, and D. A. Wargowski, "Cross-linked polyimides for integrated circuits," Proc. SPIE, vol. CR68, pp. 399-421, 1998.

[7] T. Matsuura, S. Ando, S. Sasaki, and F. Yamamoto, "Polyimides derived from 2,2'-bis(trifluoromethyl)-4,4'-diaminobiphenyl. 4. Optical properties of fluorinated polyimides for optoelectronic components," Macromolecules, vol. 27, pp. 6665-6670, 1994.

[8] K. S. Han, D.-B. Kim, W.-H. Jang, and T. H. Rhee, "Chloro-fluorinated polyimides for low loss optical waveguides application,” Jpn. J. Appl. Phys. 2, Lett., vol. 38, pp. L1249-L1251, 1999.

[9] J.-W. Kang, J.-J. Kim, J. Kim, X. Li, and M.-H. Lee, "Low-loss and thermally-stable TE-mode selective polymer waveguides using photosensitive fluorinated polyimide," IEEE Photonic Technol. Lett., vol. 14, no. 9, pp. 1297-1299, Sep. 2002.

[10] R. Yoshimura, M. Hikita, S. Tomaru, and S. Imamura, "Low-loss polymeric optical waveguides fabricated with deuterated polyfluoromethacrylate," J. Lightw. Technol., vol. 16, no. 6, pp. 1030-1037, Jun. 1998 .
[11] M. Usui, M. Hikita, T. Watanabe, M. Amano, S. Sufawara, S. Hayashida, and S. Imamura, "Low-loss passive polymer optical waveguides with high environmental stability," J. Lightw. Technol., vol. 14, no. 10, pp. 2338-2343, Oct. 1996.

[12] J.-W. Kang, J.-S. Kim, and J.-J. Kim, "Optimized oxygen plasma etching of polycarbonate for low-loss optical waveguide fabrication," Jpn. J. Appl. Phys. 1, Regul. Rap. Short Notes, vol. 40, pp. 3215-3219, 2001.

[13] J.-W. Kang, J.-S. Kim, C.-M. Lee, E. Kim, and J.-J. Kim, " $1 \times 2$ alloptical switch using photochromic-doped waveguides," Electron. Lett., vol. 36, pp. 1641-1643, 2000.

[14] J.-W. Kang, J.-J. Kim, and E. Kim, "All-optical Mach-Zehnder modulator using a photochromic dye-doped polymer," Appl. Phys. Lett., vol. 80, pp. 1710-1712, 2002.

[15] M. C. Oh, H. J. Lee, M. H. Lee, J. H. Ahn, and S. G. Han, "Polymeric wavelength filters with polymer gratings," Appl. Phys. Lett., vol. 72, pp. $1559-1561,1998$.

[16] J.-P. Kim, W.-Y. Lee, J.-W. Kang, S.-K. Kwon, J.-J. Kim, and J.-S. Lee, "Fluorinated poly(arylene ether sulfide) for polymeric optical waveguide devices," Macromolecules, vol. 34, pp. 7817-7821, 2001.

[17] J.-W. Kang, J.-P. Kim, W.-Y. Lee, J.-S. Kim, J.-S. Lee, and J.-J. Kim, "Low-loss fluorinated poly(arylene ether sulfide) waveguides with high thermal stability," J. Lightw. Technol., vol. 19, no. 6, pp. 872-875, Jun. 2001.

[18] H.-J. Lee, M.-H. Lee, M.-C. Oh, J.-H. Ahn, and S. G. Han, "Crosslinkable polymers for optical waveguide devices. II. Fluorinated ether ketone oligomers bearing ethyl group at the chanin end," J. Polym. Sci. A, Poly. Chem., vol. 37, pp. 2355-2361, 1999.

[19] A. A. Goodwin, F. W. Mercer, and M. T. McKenzie, "Thermal behavior of fluorinated aromatic polyethers and poly(ether ketone)s," Macromolecules, vol. 30, pp. 2767-2774, 1997.

[20] J.-W. Kang, J.-P. Kim, J.-S. Kim, J.-S. Lee, and J.-J. Kim, "Low-loss polymer optical waveguides using fluorinated poly(arylene ether sulfides and sulfones)," Proc. SPIE, vol. 4905, pp. 9-18, 2002.

[21] J.-P. Kim, J.-W. Kang, J.-J. Kim, and J.-S. Lee, "Fluorinated poly(arylene ether sulfone) for optical waveguide devices," Polymer, vol. 44, pp. 4189-4195, 2003.

[22] C.-C. Teng, "Precision measurements of the optical attenuation profile along the propagation path in thin-film waveguides," Appl. Opt., vol. 32, pp. 1051-1054, 1993.

[23] D. W. Van Krevelen, Ed., Properties of Polymers, Their Estimation and Correlation With Chemical Structure. New York: Elsevier, 1976.

[24] H.-C. Liou, P. S. Ho, and A. Mckerrow, "The effect of crosslinking on thermal and mechanical properties of perfluorocyclobutane aromatic ether polymers," J. Polym. Sci. B, Polym. Phys., vol. 36, pp. 1383-1392, 1998.

[25] J. D. Swalen, "Calculation of indices of refraction of photonic polymers," Proc. SPIE, vol. 3799, pp. 301-307, 1999.

[26] D. Bhaumik, H. H. Jaffe, and J. E. Mark, "Polarizabilities of some benzobisoxazole and benzobisthiazole rigid-rod polymers," Macromolecules, vol. 14, pp. 1125-1126, 1981.

[27] L. Lin and A. J. Bidstrup, "Processing effects on optical anisotropy in spin-coated polyimide films," Appl. Poly. Sci., vol. 49, pp. 1277-1289, 1993.

[28] J. C. Pincenti, S. Goel, and D. L. Naylor, "Thermally induced birefringence and stress in poly(methyl methacrylate) waveguides on oxidized silicon substrate," Appl. Opt., vol. 32, pp. 322-326, 1993.

[29] J. C. Coburn, M. T. Pottiger, S. C. Noe, and S. D. Senturia, "Stress in polyimide coatings," J. Polym. Sci. B, Polym. Phys., vol. 32, pp. 1271-1283, 1994.

[30] J. C. Pincenti and D. L. Naylor, "Humidity dependence of the birefringence in poly(methyl-methacrylate) waveguides," Appl. Opt., vol. 33, pp. 1090-1094, 1994.

[31] B. Li, T. He, M. Ding, P. Zhang, F. Gao, and F. Jing, "Optical anisotropy of flexible polyimide thin film," J. Mater. Res., vol. 13, pp. 1368-1372, 1998.

[32] T. Watanabe, N. Ooba, Y. Hida, and M. Hikita, "Influence of humidity on refractive index of polymer waveguide and its temperature dependence," Appl. Phys. Lett., vol. 72, pp. 1533-1535, 1998.

[33] A. Tagaya, S. Iwata, E. Kawanami, H. Tsukahara, and Y. Koike, "Anisotropic molecule dopant method for synthesizing a zero-birefringence polymer," Jpn. J. Appl. Phys. 1, Regul. Rap. Short Notes, vol. 40, pp. 6117-6123, 2001.

[34] Y. H. Min, M.-H. Lee, and J. Y. Do, "Polarization dependent loss in polymeric rib channel waveguide," IEEE Photon. Technol. Lett., vol. 12, no. 11 , pp. 1483-1485, Nov. 2000. 


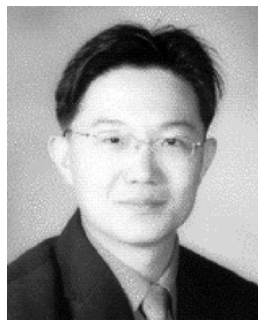

Jae-Wook Kang received the B.S. degree in materials science and engineering from Pusan National University, Korea, in 1997, and the M.S. and Ph.D. degrees in materials science and engineering from Kwangju Institute of Science and Technology (K-JIST), Kwangju, Korea, in 1999 and 2003, respectively.

$\mathrm{He}$ is currently a Postdoctoral Fellow in the Department of Materials Science and Engineering at the University of Washington, Seattle. His research areas include passive and active polymer optical waveguide devices from organic materials. He has published more than 20 papers, holds five patents, and presented more than ten times in the international conferences.

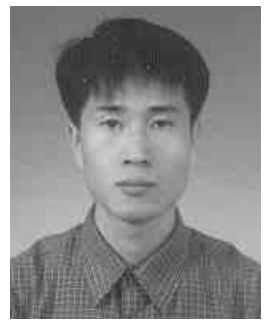

Jae-Pil Kim received the B.S. and M.S. degree in forestry from Chonbuk National University, Chonbuk, Korea, in 1997 and 1999, respectively, and the Ph.D. degree in materials science and engineering from Kwangju Institute of Science and Technolog (K-JIST), Kwangju, Korea, in 2002.

$\mathrm{He}$ is currently with Korea Photonics Technology Institute (KOPTI), Kwangju, Korea, in 2003. His research areas include functional polymer synthesis.

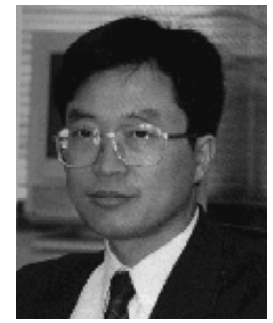

Jae-Suk Lee received the B.S. degree in chemical engineering from Chonnam National University, Chonnam, Korea, in 1979, the M.S. degree in chemical engineering from Korea Advanced Institute of Science and Technology (KAIST), Daejeon, Korea, in 1981, and the Ph.D. degree from the Tokyo Institute of Technology, Tokyo, Japan, in 1989.

He was a Special Researcher with the Institute of Physical and Chemical Research (RIKEN), Wako, Japan, from 1989 to 1992. From 1999 to 2000, he was a Visiting Professor with the Virginia Polytechnic Institute and State University, Blacksburg. He is currently a Professor in the Department of Materials Science and Engineering, Kwangju Institute of Science and Technology (K-JIST), Kwnagju, Korea. His research areas include anionic living polymerization, polymeric photonics materials, and environmentally friendly and energy-related materials.

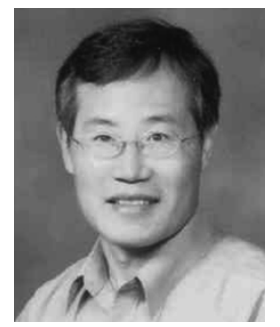

Jang-Joo Kim received the B.S. and M.S. degrees from the Department of Chemical Engineering, Seoul National University, Seoul, Korea, in 1977 and 1980, respectively, and the Ph.D. degree from the Department of Materials Science and Engineering, Stanford University, Stanford, CA, in 1987.

After one and half years as a Postdoctoral Fellow in SRI International (1986-1987), he returned to Korea and was with the Electronics and Telecommunications Research Institute (ETRI) as a Senior Member and a Principal Member of Technical Staff until 1996. He was a Professor of the Kwangju Institute of Science and Technology (K-JIST), Kwnagju, Korea, from 1997 to 2003 and is currently a Professor in the School of Materials Science and Engineering at Seoul National University. Seoul, Korea. He has published more than 90 papers and holds over 30 patents. His research areas include polymer waveguide devices, plastic optical fiber, and organic electronics.

Dr. Kim has given more than 80 presentations in international conferences, including 28 invited talks. 